\title{
Aquisição da coda vibrante: $o$ estabelecimento de pistas fonético-acústicas
}

\author{
Vibrant coda acquisition: the establishment of \\ acoustic-phonetic cues
}

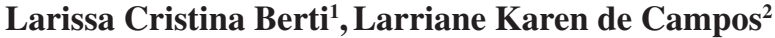

\begin{abstract}
RESUMO
Objetivo: Caracterizar acusticamente as produções da coda vibrante julgadas auditivamente como alvo; identificar a existência ou não de contrastes encobertos, nas produções julgadas auditivamente como tendo omissão da coda vibrante; e, quando existentes, caracterizar de que modo são marcados acusticamente na fala. Métodos: Foram extraídas de um banco de dados, com o uso do software PRAAT, palavras produzidas por 30 crianças (3-4 anos) em desenvolvimento normal, que continham a coda vibrante medial na sílaba tônica, no contexto das vogais /i/, /a/ e /u/. Após a caracterização perceptivo-auditiva das produções, realizou-se uma análise acústica a partir das trajetórias formânticas (F1, F2 e F3) e duração relativa da sílaba que envolvia a coda vibrante. Os dados foram estatisticamente analisados. Resultados: $\mathrm{Na}$ análise perceptivo-auditiva, 77,8\% de produções foram julgadas como alvo, $12,2 \%$ como omitidas, e $10 \%$ como substituídas, variando em função do contexto vocálico. Na análise acústica das produções alvo, verificou-se que as crianças utilizam preferencialmente os parâmetros relativos à trajetória formântica de F2 e F3 para marcarem a aquisição dessa estrutura. Analogamente, na análise acústica das produções julgadas como omitidas, contatou-se a presença de contrastes encobertos, marcados pela intercepção dos parâmetros adotados. Conclusão: A análise acústica mostra-se um recurso necessário e imprescindível para a descrição e caracterização do modo pelo qual as crianças iniciam o domínio das pistas fonético-acústicas até atingirem o contraste efetivo da coda vibrante.
\end{abstract}

Descritores: Acústica da fala; Criança; Linguagem infantil; Fonética; Medida da produção da fala

\section{INTRODUÇÃO}

Do ponto de vista fonológico, a sílaba é uma unidade dotada de constituintes hierarquicamente organizados, a saber: um ataque e uma rima que, por sua vez, pode ser ramificada em núcleo e $\operatorname{coda}^{(1)}$. Para cada constituinte silábico há uma padronização específica de quais e quantos segmentos podem ocorrer em cada posição. No caso do Português Brasileiro (doravante $\mathrm{PB}$ ), a posição de coda pode ser preenchida pelas consoantes vibrante $/ \mathrm{R} /$, lateral $/ \mathrm{L} /$, fricativa $/ \mathrm{S} /$ e nasal $/ \mathrm{N} /{ }^{2}$ ).

A aquisição da coda vibrante, particularmente, tem sido unanimemente apontada como tendo um domínio complexo e tardio por parte das crianças ${ }^{(3-8)}$. Esse domínio complexo e

Trabalho realizado no Departamento de Fonoaudiologia, Universidade Estadual Paulista "Júlio de Mesquita Filho" - UNESP - Marília (SP), Brasil. Conflito de interesses: Não

(1) Departamento de Fonoaudiologia, Universidade Estadual Paulista "Júlio de Mesquita Filho" - UNESP - Marília (SP), Brasil.

(2) Curso de Fonoaudiologia, Universidade Estadual Paulista "Júlio de Mesquita Filho" - UNESP - Marília (SP), Brasil.

Endereço para correspondência: Larissa Cristina Berti. Av. Hygino Muzzi

Filho, 737, Campus Universitário, Marília (SP), Brasil, CEP: 17525-900.

E-mail: berti.larissa@gmail.com

Recebido em: 9/5/2011; Aceito em: 10/11/2011 tardio é explicado por envolver tanto um padrão silábico complexo (CVC), quanto um movimento articulatório complexo (em suas diferentes realizações fonéticas*).

$\mathrm{Na}$ tentativa de compreender o processo de aquisição da coda vibrante, diversos estudos têm se ocupado com essa temática, enfocando tanto sua aquisição típica quanto desviante, a partir de diferentes perspectivas ${ }^{(7,8,10-14)}$.

No tocante à descrição da aquisição típica da coda vibrante no PB, um estudo ${ }^{(10)}$ constatou que as crianças comumente utilizam uma alta porcentagem de estratégias de reparo na tentativa de se aproximar do sistema fonológico alvo. Conforme descrição da autora ${ }^{(10)}$, as estratégias de reparo mais comumente utilizadas pelas crianças na tentativa de produzir essa estrutura referem-se à semivocalização, substituição, epêntese, além do alongamento da vogal.

Estudo recente ${ }^{(8)}$ descreveu, com o uso da análise acústica, que nas produções julgadas como tendo omissão da coda vibrante o alongamento da vogal é um dos recursos compensatórios mais utilizados pelas crianças na tentativa de

*Destaca-se que a coda vibrante no PB pode ser realizada foneticamente como vibrante alveolar sonora, vibrante alveolar surda, retroflexa alveodental surda, alveodental sonora, retroflexa palatoalveolar e palatal, uvular sonora ${ }^{(9)}$. 
produção alvo. Isso indica que as crianças já apresentam algum conhecimento a respeito dessa estrutura silábica.

Quanto à descrição da aquisição desviante da coda vibrante, a autora de um estudo ${ }^{(12)}$ identificou e descreveu, com o uso da análise acústica, um achado significativo referente às tentativas da criança de se aproximar da produção alvo. Tal achado refere-se ao fato de que muitas das produções da coda vibrante julgadas auditivamente como sendo uma substituição categórica pela semivogal /j/, trata-se de um contraste fônico encoberto, ou seja, um contraste fônico imperceptível auditivamente, mas detectável acústica e/ou articulatoriamente ${ }^{(15)}$. Nessas "aparentes" substituições, os contrastes encobertos foram marcados pelos parâmetros acústicos de duração relativa, trajetórias formânticas de F1, F2 e F3 ${ }^{(12)}$. A não detecção do contraste encoberto na análise perceptivo-auditiva, é explicada no estudo pelo fato de "a nossa percepção - relacionada às unidades fônicas - ser direcionada pelas categorias do sistema fônico do adulto"(12).

Desse modo, nos estudos citados, verifica-se o constante destaque ao uso da análise acústica para uma descrição mais detalhada do processo de aquisição da coda vibrante, uma vez que ela possibilita a apreensão dos contrastes encobertos (marcados pelas estratégias de reparo) utilizados pelas crianças. Tais contrastes, por sua vez, parecem ser constitutivos do processo de aquisição fônica.

No entanto, há ainda para o PB uma escassez de estudos que enfoquem a aquisição típica da coda vibrante, considerando o modo pelo qual as crianças se apropriam das pistas fonético-acústicas para atingir o contraste alvo da língua. Com efeito, a proposta do presente estudo centra-se em descrever e caracterizar acusticamente o processo típico de aquisição da coda vibrante, em sua variante aproximante retroflexa. Especificamente, os objetivos foram: caracterizar acusticamente as produções das crianças julgadas auditivamente como típicas (alvo) da coda vibrante; identificar a existência ou não de contrastes encobertos, nas produções da coda vibrante julgadas auditivamente como omitidas; e, quando existentes, caracterizar de que modo esses contrastes encobertos são marcados acusticamente na fala.

Acredita-se que o desenvolvimento desse estudo poderá trazer contribuições para a compreensão do processo de aquisição da coda vibrante e fornecer maiores informações sobre a presença de contrastes encobertos como uma "etapa" no processo de aquisição de um determinado contraste fonológico. Além disso, poderá trazer contribuições acerca de quais são os parâmetros acústicos utilizados pelas crianças para marcar o contraste fonológico envolvendo a coda vibrante, em sua variedade aproximante retroflexa.

\section{MÉTODOS}

As produções das codas vibrantes analisadas foram extraídas de amostras de fala que integram um Banco de Dados Acústicos Digitalizados organizados por integrantes do Grupo de Pesquisa de Estudos sobre a Linguagem (GPEL). A constituição do referido banco teve sua aprovação pelo Comitê de Ética em Pesquisa da Universidade Estadual Paulista "Júlio de Mesquita Filho" (UNESP Marília), sob o protocolo de número 132/2010.
O banco consiste de gravações de 120 crianças que frequentavam a Escola Municipal de Educação Infantil Sítio do Pica-Pau Amarelo, da cidade de Marília. As gravações foram feitas com o uso de equipamentos de alta fidelidade, com cada criança individualmente, no interior de uma cabine acústica instalada na própria instituição. Para eliciar a amostra que constituiu o banco de dados foi utilizado o Instrumento de Avaliação de Fala para Análise Acústica (IAFAC) ${ }^{(16)}$, o qual engloba a produção de palavras contendo todos os fonemas do sistema fonológico do PB, considerando tanto a posição de ataque quanto a posição de coda silábica. As palavras do IAFAC foram inseridas na frase-veículo "Fala (palavra alvo) bem bonito" para que as crianças pudessem repeti-las após a apresentação concomitante das pistas visual e auditiva correspondentes às palavras-alvo.

Desse banco, foram selecionadas para a realização dessa pesquisa, gravações de 30 crianças que frequentavam o Pré II da Escola Municipal de Educação Infantil Sítio do Pica-Pau Amarelo. Os critérios de inclusão dos sujeitos foram: ter idades entre 3 e 4 anos; não apresentar alterações neurológica, cognitiva e de linguagem; ter audição normal**; além de apresentar, a partir do Termo de Consentimento Livre e Esclarecido, uma autorização por escrito dos responsáveis.

Foram selecionados, com o uso do software PRAAT, os arquivos de áudio relativos às produções da coda vibrante no contexto posposto às vogais tônicas $/ \mathrm{i} /, / \mathrm{a} / \mathrm{e} / \mathrm{u} /$, correspondendo às produções das palavras "circo", "carta" e "curto" e os arquivos de áudio relativos às produções das palavras "rico", "lata" e "pluto", pelo fato de constituírem pares análogos às palavras alvo. Esta última seleção foi feita para possibilitar a comparação entre a rima silábica das palavras julgadas como tendo omissão de coda com a rima silábica das palavras em que a posição de coda não era preenchida.

Especificamente, as seguintes comparações foram feitas para contemplar os três objetivos do trabalho:

- [i.t], de ['si.tku], julgado como alvo, em oposição à [i], de ['riku];

- [aut], de ['kauta], julgado como alvo, em oposição à [a], de ['lata];

- [u.t], de ['ku.tu], julgado como alvo, em oposição à [u], de ['plutu];

- [i], de ['siku], julgado como tendo omissão de coda, em oposição à [i], de ['riku];

- [a], de ['kata], julgado como tendo omissão de coda, em oposição à [a], de ['lata];

- [u], de ['kuto], julgado como tendo omissão de coda, em oposição à [u], de ['plutu].

Contudo, levando-se em consideração as gravações de 30 crianças, computou-se um total de 180 realizações, sendo 90 produções de palavras que envolviam a posição de coda preenchida pela vibrante ( 30 gravações de crianças $\mathrm{x}$ três palavras: circo, carta, curto) e 90 produções que não envolviam a produção da coda (30 gravações de crianças $x$ três palavras: rico, lata, pluto).

Após a seleção da amostra, foi feita uma caracterização perceptivo-auditiva das produções, com base na transcrição

\footnotetext{
**Todas as crianças passaram por triagem audiológica.
} 
feita por cinco juízes residentes na mesma região dialetal dos participantes do presente estudo. Os juízes transcreveram as produções das crianças, a partir de três categorias: produção alvo, substituição e omissão da coda vibrante. Adotou-se um critério de concordância de $80 \%$ entre os juízes.

Posteriormente, foi feita a análise acústica de todas as amostras com a utilização do software PRAAT. Os parâmetros utilizados na análise foram: medida da trajetória formântica do primeiro, segundo e terceiro formantes (F1, F2 e F3, respectivamente), e duração absoluta e relativa da coda vibrante, conforme descrição de um estudo prévio ${ }^{(12)}$.

Para a obtenção das medidas da trajetória formântica foram considerados os valores relacionados às posições inicial, medial e final dos três primeiros formantes (F1, F2 e F3), resgatando os momentos que caracterizam tanto a produção da vogal quanto a produção da retroflexa. Os três momentos foram considerados pelo fato de não existir um ponto de seg- mentação definido entre a vogal e a retroflexa, isto é, não se pode determinar com precisão o final da vogal e/ou o início da retroflexa.

Além disso, foram calculadas as distâncias entre F3 X F2 e F2 X F1 na posição final da trajetória formântica. Essa distância foi obtida a partir da subtração dos valores: F3 - F2 na porção final da trajetória, e F2 - F1 na posição final da trajetória.

As trajetórias formânticas de F1, F2 e F3, adotadas na análise, são ilustradas nas Figuras 1 e 2.

A medida de duração utilizada na análise, por sua vez, foi a de duração relativa da coda vibrante, na tentativa de minimizar variações desse parâmetro devido a, principalmente, mudanças da taxa de locução. Por exemplo, no caso da palavra ['kauta], foram calculadas as durações absolutas da rima silábica - [ar] (elemento fônico em foco na análise) e a duração integral da palavra - ['katta], para que fosse calculada a duração relativa,

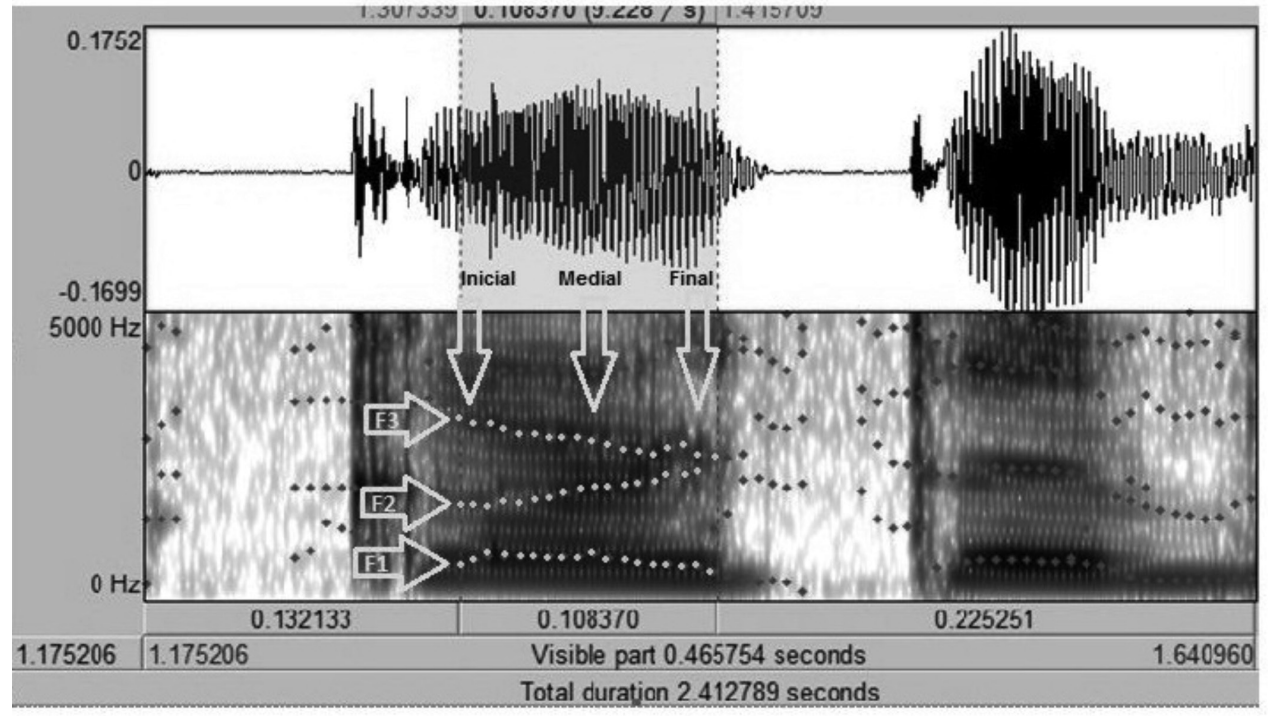

Obs.: O trecho selecionado corresponde à rima da primeira sílaba da palavra "carta".

Figura 1. Trajetória formântica adotada na análise relativa à produção da palavra "carta"

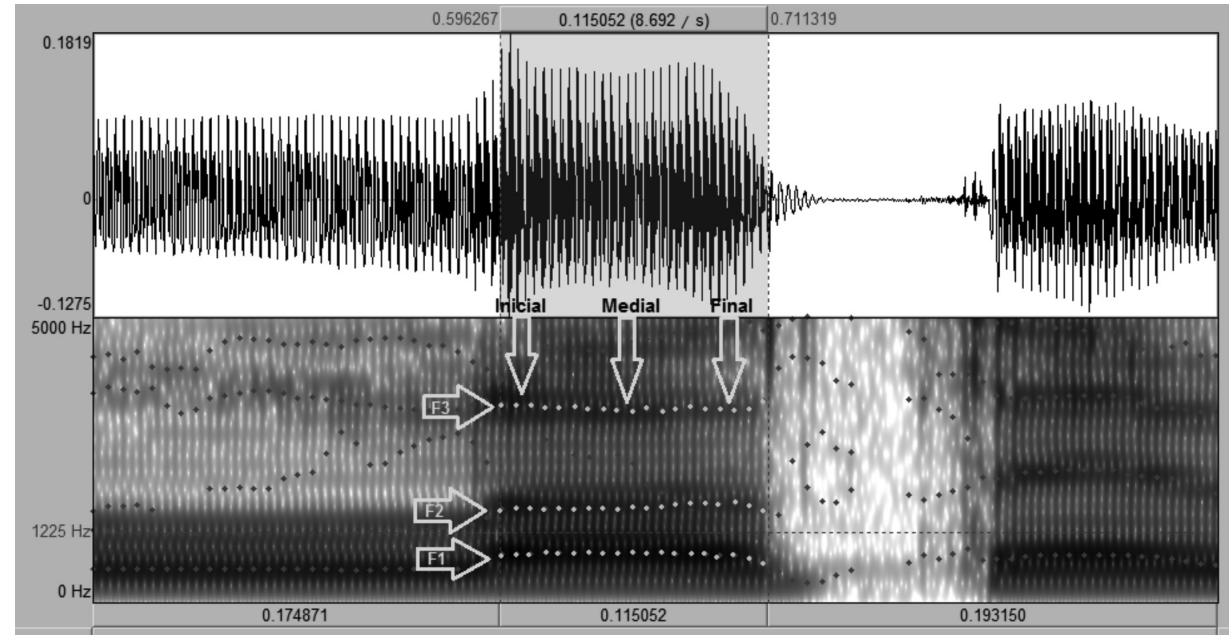

Obs: O trecho selecionado corresponde à rima da primeira sílaba da palavra "lata"

Figura 2. Trajétoria formântica adotada na análise relativa à produção da palavra "lata" 
de acordo com a seguinte equação: duração relativa = duração absoluta [a.t] X 100/duração absoluta da palavra ['ka.tta]

\section{Análise estatística}

As medidas de trajetória formântica e de duração foram analisadas utilizando-se o teste ANOVA One-way, com o uso do software Statistica versão 7.0. As variáveis dependentes consideradas foram todos os parâmetros acústicos adotados na análise, enquanto as variáveis independentes adotadas se referiram à posição de coda preenchida e não preenchida nas palavras alvos. Após a ANOVA One-way, foi utilizado um teste post-hoc, o Modelo Linear Hierárquico, para determinar $\mathrm{o}(\mathrm{s})$ parâmetro(s) acústico(s) e sua magnitude na distinção da posição de coda preenchida e não preenchida.

Os resultados com valores de $\mathrm{p}$ inferiores a $0,05(\mathrm{p}<0,05)$ foram considerados significativos. Os resultados com valores de $\mathrm{p}$ entre 0,05 e $0,1(0,05<\mathrm{p}<0,1)$ foram considerados marginais.

\section{RESULTADOS}

Primeiramente, serão apresentados os resultados concernentes à análise perceptivo-auditiva e, em seguida, serão expostos os resultados obtidos na análise acústica.

\section{Análise perceptivo-auditiva}

Estão dispostos, a seguir, os resultados da caracterização perceptivo-auditiva das produções da coda vibrante pelas crianças, em função do contexto vocálico (Tabela 1).

Tabela 1. Caracterização das produções da coda vibrante, nos três contextos vocálicos, a partir da análise de perceptivo-auditiva

\begin{tabular}{lcccc}
\hline & \multicolumn{3}{c}{ Julgamento perceptivo-auditivo } \\
\cline { 2 - 4 } Contexto & $\begin{array}{c}\text { Produções } \\
\text { vocálico }\end{array}$ & $\begin{array}{c}\text { Erros de produção da } \\
\text { coda vibrante }\end{array}$ & Total \\
\cline { 3 - 4 } & $\mathrm{n}(\%)$ & $\begin{array}{c}\text { Omissão } \\
\mathrm{n}(\%)\end{array}$ & $\begin{array}{c}\text { Substituição } \\
\mathrm{n}(\%)\end{array}$ \\
\hline la/ & $25(83,3)$ & - & $5(16,7)$ & $30(100)$ \\
li/ & $22(73,4)$ & $8(26,6)$ & $0(0)$ & $30(100)$ \\
/u/ & $24(80)$ & $3(10)$ & $3(10)$ & $30(100)$ \\
\hline Total & 71 & 11 & 8 & 90 \\
\hline
\end{tabular}

No tocante à caracterização perceptivo-auditiva das produções das crianças, verifica-se que o contexto da vogal /a/ parece ser o mais facilitador para a produção da coda vibrante em sua variedade aproximante retroflexa, seguido do contexto da vogal /u/ e, por último, o contexto da vogal /i/ (Tabela 1).

\section{Análise acústica - produções julgadas como alvo}

$\mathrm{Na}$ análise acústica das produções julgadas como alvos comparou-se os valores dos parâmetros acústicos das produções julgadas como alvo com os das produções que não apresentavam a posição de coda preenchida. Exemplificando, foram comparadas as medidas acústicas relativas à rima da primeira sílaba da palavra "circo" (equivalendo a /iR/) com a rima da primeira sílaba da palavra "rico" (equivalendo a /i/). Os resultados dessa análise estão expostos na Tabela 2.

Tabela 2. Resultados das produções julgadas como alvo na análise perceptivo- auditiva

\begin{tabular}{|c|c|c|c|c|}
\hline \multirow[t]{2}{*}{ Parâmetros acústicos } & $\begin{array}{c}\mathrm{R}^{2} \\
\text { múltiplo }\end{array}$ & $\begin{array}{c}\mathrm{R}^{2} \\
\text { ajustado }\end{array}$ & $\begin{array}{l}\text { Valor } \\
\text { de F }\end{array}$ & $\begin{array}{l}\text { Valor } \\
\text { de } p\end{array}$ \\
\hline & \multicolumn{4}{|c|}{ Vogal /i/ } \\
\hline \% duração & 0,04 & 0,01 & 1,5 & 0,23 \\
\hline F3 medial & 0,14 & 0,12 & 6,3 & $0,02^{*}$ \\
\hline F3 final & 0,05 & 0,03 & 2,27 & 0,14 \\
\hline F3 final-F2 final & 0,15 & 0,13 & 7,25 & $0,01^{*}$ \\
\hline F2 medial & 0,39 & 0,38 & 25,7 & $0,00^{*}$ \\
\hline F2 final & 0,29 & 0,27 & 16,24 & $0,00^{*}$ \\
\hline F2 final-F1 final & 0,29 & 0,28 & 16,68 & $0,00^{*}$ \\
\hline \multirow[t]{2}{*}{ F1 final } & 0,03 & 0,01 & 1,12 & 0,30 \\
\hline & \multicolumn{4}{|c|}{ Vogal /a/ } \\
\hline \% duração & 0,35 & 0,33 & 25,47 & $0,00^{*}$ \\
\hline F3 medial & 0,08 & 0,057 & 3,97 & 0,05 \\
\hline F3 final & 0,12 & 0,1 & 6,55 & $0,01^{*}$ \\
\hline F3 final-F2 final & 0,45 & 0,44 & 39,35 & $0,00^{*}$ \\
\hline F2 medial & 0,2 & 0,18 & 11,73 & $0,00^{*}$ \\
\hline F2 final & 0,36 & 0,34 & 26,51 & $0,00^{*}$ \\
\hline $\mathrm{F} 2$ final-F1 final & 0,62 & 0,61 & 78,99 & $0,00^{*}$ \\
\hline \multirow[t]{2}{*}{ F1 final } & 0,47 & 0,46 & 42,71 & $0,00^{*}$ \\
\hline & \multicolumn{4}{|c|}{ Vogal /u/ } \\
\hline \% duração & 0,02 & 0,01 & 0,86 & 0,36 \\
\hline F3 medial & 0,42 & 0,4 & 33,02 & $0,00^{*}$ \\
\hline F3 final & 0,49 & 0,48 & 43,95 & $0,00^{*}$ \\
\hline F3 final-F2 final & 0,64 & 0,63 & 80,85 & $0,00^{*}$ \\
\hline F2 medial & 0,06 & 0,04 & 2,8 & 0,1 \\
\hline F2 final & 0,11 & 0,09 & 5,68 & $0,02^{*}$ \\
\hline F2 final-F1 final & 0,15 & 0,14 & 8,4 & $0,01^{*}$ \\
\hline F1 final & 0,07 & 0,05 & 3,64 & 0,06 \\
\hline
\end{tabular}

Verifica-se, pois, que no contexto das vogais /i/ e /u/, cinco dos oito parâmetros acústicos foram sensíveis para diferenciar a rima silábica contendo a coda vibrante e a rima silábica sem a posição de coda preenchida. No contexto da vogal /a/, por sua vez, verifica-se que a maior parte dos parâmetros acústicos (sete dos oito parâmetros) foi utilizada para marcar o preenchimento da coda vibrante. Destaca-se, ainda, que tanto os valores de $\mathrm{p}$ quanto os valores de $\mathrm{F}$ das pistas acústicas variaram em sua magnitude, ou seja, há parâmetros acústicos que apresentaram maior valor de $\mathrm{Fe}$, consequentemente, maior significância estatística.

\section{Análise acústica - produções julgadas como tendo omissão}

Foram comparados, nos contextos das vogais /i/ e /u/, os valores dos parâmetros acústicos das produções julgadas como tendo omissão da coda vibrante com os valores dos parâmetros acústicos das produções das palavras em que não 
havia a posição de coda preenchida. Exemplificando, foram comparados os valores relativos à rima da primeira sílaba da palavra ['siku], julgada como omissão da coda (equivalendo a /i/), com a rima da primeira sílaba da palavra "rico" (equivalendo a /i/). A seguir, sintetiza os resultados obtidos nessa comparação (Tabela 3). Ressalta-se ao leitor que o contexto da vogal /a/ não foi analisado pelo fato de não ter apresentado nenhuma produção da coda vibrante julgada como omitida.

Tabela 3. Resultados para as produções julgadas como omissão na análise perceptivo-auditiva

\begin{tabular}{lcccc}
\hline \multirow{2}{*}{ Coeficientes } & $\mathrm{R}^{2}$ múltiplo & $\mathrm{R}^{2}$ ajustado & Valor de $\mathrm{F}$ & Valor de $\mathrm{p}$ \\
\cline { 2 - 5 } \% duração & 0 & $-0,07$ & 0,04 & 0,84 \\
F1 final & 0 & $-0,07$ & 0 & 0,99 \\
F2 - F1 final & 0,01 & $-0,06$ & 0,19 & 0,67 \\
F2 medial & 0,2 & 0,14 & 3,47 & $0,08^{\star \star}$ \\
F2 final & 0,01 & $-0,06$ & 0,18 & 0,68 \\
F3 - F2 final & 0,02 & $-0,05$ & 0,34 & 0,57 \\
F3 medial & 0 & $-0,07$ & 0 & 0,96 \\
F3 final & 0,02 & $-0,05$ & 0,31 & 0,58 \\
Intercepção & - & - & 719 & $0,00^{*}$ \\
\hline & \multicolumn{4}{c}{ Vogal /u/ } \\
\hline \% duração & 0,84 & 0,77 & 10,87 & $0,08^{\star *}$ \\
F1 final & 0,14 & $-0,28$ & 0,34 & 0,62 \\
F2 - F1 final & 0,34 & 0,01 & 1,02 & 0,42 \\
F2 medial & 0,29 & $-0,06$ & 0,82 & 0,46 \\
F2 final & 0,3 & $-0,05$ & 0,87 & 0,45 \\
F3 - F2 final & 0,39 & 0,09 & 1,29 & 0,37 \\
F3 medial & 0,1 & $-0,35$ & 0,22 & 0,68 \\
F3 final & 0,03 & $-0,46$ & 0,05 & 0,84 \\
Intercepção & - & - & 882344,7 & $0,00^{*}$ \\
\hline
\end{tabular}

*Valores significativos $(\mathrm{p}<0,05)$ - ANOVA One-way

** Valores marginais $(0,05<\mathrm{p}<0,1)$ - ANOVA One-way

Verifica-se, no contexto da vogal /i/, que a intercepção do conjunto dos parâmetros juntamente com F2 na posição medial se mostraram relevantes para marcar a distinção entre a "aparente omissão" da coda vibrante e a posição de coda não preenchida. Já no contexto da vogal /u/, observa-se que tanto a intercepção dos parâmetros, quanto a duração relativa (ainda que com um valor marginal de p) foram utilizadas para distinguir a "aparente omissão" e a posição de coda não preenchida.

\section{DISCUSSÃO}

Considerando o julgamento perceptivo-auditivo das produções das crianças, verifica-se como tendência geral que $77,8 \%$ das produções foram julgadas como alvo, $12,2 \%$ como omitidas e $10 \%$ como substituídas, corroborando o estudo anterior ${ }^{(10)}$, o qual descreve que a aquisição da coda vibrante medial ocorre por volta dos 3 anos e 10 meses. Outro resultado a ser destacado na análise perceptivo-auditiva refere-se ao fato de as omissões, de modo geral, serem mais recorrentes que as substituições. Esse achado concorda, mais uma vez, com o estudo citado anteriormente ${ }^{(10)}$, o qual descreve que a estratégia de omissão é muito frequente na aquisição da coda vibrante medial. Esse fato é possivelmente explicado devido tanto à complexidade silábica (CVC) quanto à complexidade articulatória ${ }^{(3,4,7,8)}$.

Conforme descrito, os resultados do julgamento perceptivo-auditivo variaram em função do contexto vocálico. $\mathrm{O}$ contexto da vogal $/ \mathrm{a} /$, especificamente, parece ser favorecedor na aquisição, visto que $83 \%$ das produções foram julgadas como alvo, $17 \%$ como substituídas, não havendo produções julgadas como omitidas. Esses resultados concordam, em grande parte, com pesquisas prévias ${ }^{(5,8)}$. No primeiro estudo ${ }^{(5)}$, constatou-se que os contextos das vogais /a/ e /o/ apresentam maior incidência de produções corretas da líquida não lateral. No segundo estudo ${ }^{(8)}$, verificou-se que a combinação de sons oclusivos com a vogal /a/ é facilitadora para a aquisição da coda $/ R /$. No entanto, esses achados discordam daqueles encontrados em um estudo anterior ${ }^{(10)}$, em que os contextos vocálicos mais favorecedores para a produção da coda medial referiram-se à $/ \varepsilon / \mathrm{e} / \mathrm{i} /$, ao invés de $/ \mathrm{a} /$.

No tocante à análise acústica das produções julgadas como alvo, verificou-se que nem todos os parâmetros acústicos foram utilizados para marcar o contraste entre a rima silábica preenchida e não preenchida pela coda vibrante. Particularmente, no contexto da vogal /a/, 87,5\% dos parâmetros (sete dos oito parâmetros) foram utilizados para marcar a produção da coda vibrante, enquanto no contexto das vogais /i/ e /u/, apenas 62,5\% (cinco dos oito parâmetros) apresentaram significância.

Esse achado justifica-se, possivelmente, devido às questões neuromaturacionais. As crianças participantes deste estudo estavam em processo de maturação neuromotora, não apresentando, ainda, uma estabilização na produção de fala. Estudos anteriores, por exemplo, alertam para o fato de que a neuromaturação das estruturas orofaciais é um processo que pode interferir na produção de fala, uma vez que está diretamente ligada à mobilidade de estruturas como, por exemplo, a língua e os lábios, imprescindíveis à produção da fala ${ }^{(17-20)}$.

Um segundo destaque referente à caracterização acústica das produções alvo, diz respeito ao tipo e a magnitude das pistas acústicas utilizadas pelas crianças. Constatou-se que as crianças não utilizam as pistas acústicas de modo equivalente, sugerindo uma hierarquia organizacional dessas pistas, tal como descrita em estudos prévios ${ }^{(21-23)}$.

A partir da análise estatística post-hoc, infere-se que quanto maior os valores de $\mathrm{p}$ e de $\mathrm{F}$ obtidos em cada parâmetro acústico, maior a robustez na diferenciação da rima silábica que apresenta a coda vibrante e a rima silábica que não apresenta a posição de coda preenchida. Assim sendo, torna-se possível detectar quais são os parâmetros acústicos mais e menos robustos na diferenciação do contraste entre a posição preenchida e não preenchida da coda vibrante. Dito de outro modo, constata-se a existência de parâmetros acústicos que podem ser caracterizados como pistas acústicas primárias - parâmetros que apresentam uma maior magnitude de $\mathrm{p}$ e maior valor de $\mathrm{F}$, e parâmetros acústicos que podem ser caracterizados como pistas acústicas secundárias - parâmetros que apresentam uma menor magnitude de $\mathrm{p}$ e menor valor de $\mathrm{F}$ na diferenciação da rima silábica com e sem o preenchimento da coda vibrante.

Com efeito, considerando-se todos os contextos vocálicos, propõem-se como parâmetros acústicos primários (pistas primárias) para caracterizar a produção da coda vibrante, em sua 


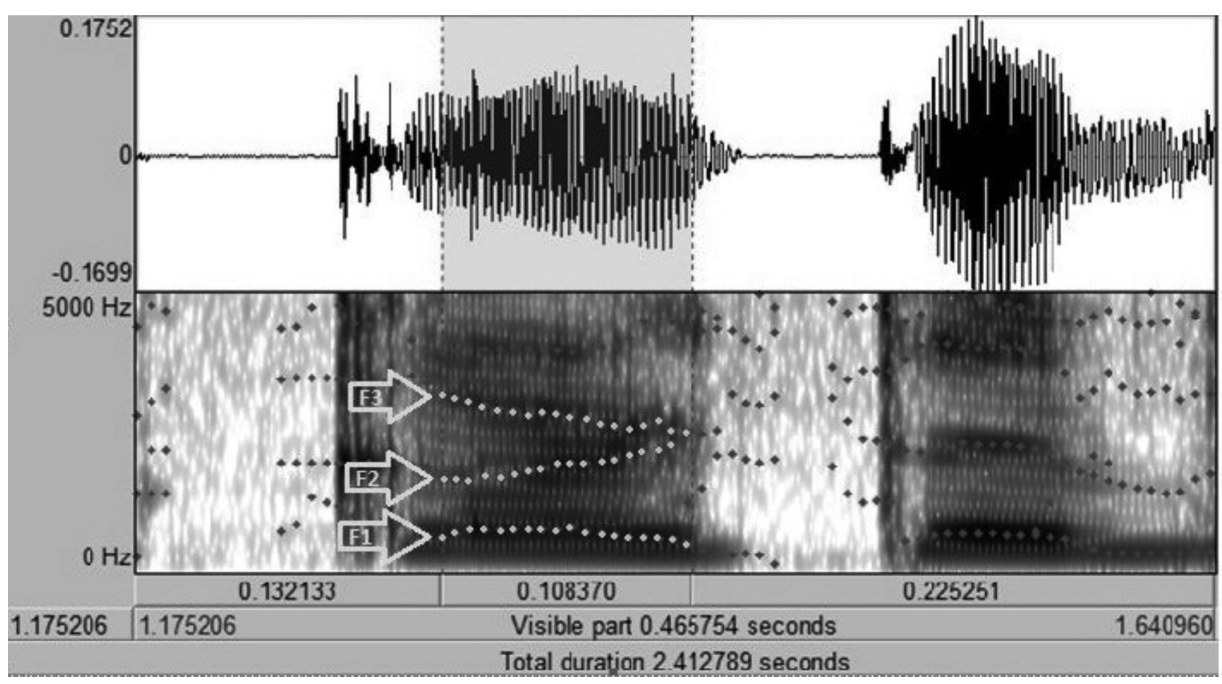

Obs: O trecho selecionado corresponde à rima da primeira sílaba da palavra "carta", em que pode ser observada uma queda em F3, que é característica do movimento de retroflexão presente na produção da coda silábica e o movimento concomitante de subida de F2

Figura 3. Forma da onda e espectrograma de uma produção alvo, da palavra "carta"

variante aproximante retroflexa, a diferença entre a posição final da trajetória de $\mathrm{F} 3$ e F2, e a diferença entre a posição final da trajetória de F2 e F1, correspondendo ao padrão acústico de movimento de abaixamento de F3 concomitante ao movimento de subida de F2. Esses parâmetros primários, por sua vez, ilustram o uso recorrente do seguinte padrão acústico identificado na análise das produções alvo: movimento concomitante de abaixamento de F3 e subida de F2, conforme o exemplo apresentado na Figura 3.

Já como parâmetros acústicos secundários propõem-se: a medida de F2 na posição medial da trajetória formântica, a medida de F3 na posição medial da trajetória formântica e a medida de F3 na posição final da trajetória formântica.

Embora para o Inglês Americano o parâmetro acústico descrito como o mais importante para caracterizar a produção da aproximante retroflexa seja o abaixamento de $\mathrm{F}^{(24)}$, estudos que descreveram a produção da aproximante retroflexa no $\mathrm{PB}^{(12,25)}$ encontraram um padrão similar ao descrito no presente estudo, ou seja, aproximação das trajetórias formânticas de F3 e F2, não necessariamente devido - apenas - ao abaixamento de F3, mas também à elevação concomitante de F2. Mais recentemente, outro estudo ${ }^{(26)}$ descreveu o importante papel da trajetória de F2 na caracterização dos sons líquidos laterais e não laterais no $\mathrm{PB}$, a partir da produção de fala de crianças.

Nas análises acústicas das produções julgadas como omitidas constatou-se que as crianças em processo de aquisição da coda vibrante apresentaram contrastes encobertos na tentativa da produção alvo, corroborando estudos anteriores ${ }^{(12,27)}$. Ressalta-se, porém, que apesar de o segundo estudo denominar as tentativas das crianças para produzirem a coda vibrante alvo como estratégias de reparo, entendemos que essas estratégias caracterizam o que assumimos por contrastes encobertos.

Um último destaque a ser feito refere-se a quais parâmetros acústicos são utilizados pelas crianças em processo típico e desviante de aquisição para marcar o contraste encoberto. Identificamos, pois, que a intercepção dos parâ- metros, a duração e a medida de F2 medial caracterizaram a presença do contraste encoberto nas crianças em processo típico de aquisição. Isso significa dizer que, de forma geral, se considerarmos na análise nas produções da coda vibrante julgadas como omitidas apenas um único parâmetro, individualmente, este não será sensível - o suficiente - para detectar tal distinção.

Desse modo, considerando o conjunto de parâmetros acústicos, identificamos a presença do contraste encoberto, em ambos os contextos vocálicos, nas produções da coda vibrante julgadas como omitidas. Similarmente, de acordo com estudo anterior ${ }^{(12)}$, os parâmetros acústicos utilizados por crianças em processo de aquisição desviante foram, preferencialmente, a utilização da trajetória de F2 e a duração. Contudo, a detecção do contraste encoberto nas produções julgadas como omitidas é de extrema relevância para a área de aquisição fonológica, na medida em que permite explicitar a maneira pela qual as crianças apreendem gradativamente os parâmetros acústicos para estabelecer um determinado contraste fônico.

\section{CONCLUSÃO}

A partir do desenvolvimento da presente pesquisa, destacam-se quatro resultados principais: as crianças produzem mais os alvos que os omitem ou os substituem; o contexto da vogal /a/ apresenta-se como o mais favorecedor para a produção da coda vibrante, em sua variante aproximante retroflexa; os parâmetros acústicos primários (ou seja, os mais importantes) para a caracterização de tal estrutura foram a trajetória formântica decrescente de F3 e a trajetória formântica crescente de F2; há contrastes encobertos nas "aparentes omissões", marcados acusticamente pela interação dos parâmetros medida de duração e F2 em posição medial da trajetória.

Adicionalmente, a análise acústica mostra-se um recurso necessário e imprescindível para a descrição e caracterização do modo pelo qual as crianças iniciam o domínio das pistas 
fonético-acústicas até atingirem o contraste efetivo da coda vibrante. A identificação e descrição de tais pistas podem subsidiar, sobremaneira, a prática clínica, tanto no que se refere à caracterização da produção desviante da coda vibrante por crianças com transtorno fonológico, quanto no tocante ao processo de aquisição dessa estrutura por essas crianças durante o processo terapêutico.

\section{AGRADECIMENTOS}

Agradecemos à Fundação de Amparo à Pesquisa do Estado de São Paulo (FAPESP), pelo apoio concedido para realização dessa pesquisa, sob o processo número (06/61816-4; 10/00854-1).

\begin{abstract}
Purpose: To acoustically characterize the target productions of vibrant coda; to identify the presence (or not) of covert contrasts in productions omitting the vibrant coda; and to characterize how these contrasts are acoustically marked in speech. Methods: Recordings of words produced by 30 children (3-4 years old) with typical language development were selected from a database using the software PRAAT. The words analyzed involved the production of the medial vibrant coda in stressed position, in the context of vowels /i/, /a/, and /u/. After auditory-perceptual characterization of the productions, an acoustic analysis was conducted considering the formant trajectory (F1, F2 and F3) and the relative length of the syllable containing the vibrant coda. Data were statistically analyzed. Results: In the auditory-perceptual analysis, $77.8 \%$ of the productions were identified as the target vibrant coda, $12.2 \%$ were omitted, and $10 \%$ were substituted, varying according to the vowel context. In the acoustic analysis of target productions, it was verified that children preferably used acoustic parameters related to the formant trajectory of F2 and F3 to mark the acquisition of this structure. Analogously, in the acoustic analysis of omitted productions, it was identified the presence of covert contrasts, marked by the interception of the adopted acoustic parameters. Conclusion: Acoustic analysis seems to be a necessary and indispensable resource for describing and characterizing how children start mastering acoustic-phonetic cues, until they reach the effective contrast of the vibrant coda.
\end{abstract}

Keywords: Child; Speech acoustics; Phonetics; Child language; Speech production measurement

\section{REFERÊNCIAS}

1. Selkirk EO. The syllable. In: Van Der Hulst H, Smith N (Editors). The structure of phonological representations (part II). Dordrecht, Holland: Foris Publications; 1982. p. 337-83.

2. Camara Jr JM. Estrutura da língua portuguesa. Petrópolis: Vozes, 1970.

3. Miranda AR. A aquisição das líquidas não-laterais no português do Brasil. Letras de Hoje. 1998;33(2):123-31.

4. Magalhães JS. Omissão da líquida não-lateral e opacidade na aquisição do português brasileiro. Letras \& Letras. 2002;18(2):85-102.

5. Keske-Soares M, Mota HB, Pagliarin KC, Ceron MI. Estudo sobre os ambientes favoráveis à produção da líquida não-lateral /r/ no tratamento do desvio fonológico. Rev Soc Bras Fonoaudiol. 2007;12(1):48-54.

6. Athayde ML, Baesso JS, Dias RF, Giacchini V, Mezzomo CL. O papel das variáveis extralinguísticas idade e sexo no desenvolvimento da coda silábica. Rev Soc Bras Fonoaudiol. 2009;14(3):293-9.

7. Mezzomo CL, Quintas VG, Savoldi A, Bruno LB. Aquisição da coda: um estudo comparativo entre dados transversais e longitudinais. Rev Soc Bras Fonoaudiol. 2010;15(3):401-7.

8. Maldonade IR, Mota HB. Alongamento vocálico e apagamento em coda medial nos desvios fonológicos. Pró-Fono. 2010;22(1):61-6.

9. Cagliari LC. Elementos de fonética do português brasileiro. São Paulo: Paulistana Editora, 2007.

10. Mezzomo CL. Sobre a aquisição da coda. In: Lamprecht RR et al. Aquisição fonológica do português: perfil de desenvolvimento e subsídios pra terapia. Porto Alegre: Artmed; 2004. p.129-50.

11. Mezzomo CL. O uso de estratégia de reparo como indício do conhecimento fonológico da criança. In: Bonilha GF, Keske-Soares M. Estudos em aquisição fonológica. Santa Maria: PPGL Editores; 2007. p. $65-80$

12. Rodrigues LL. Aquisição dos róticos em crianças com queixa fonoaudiológica [dissertação]. Campinas. Universidade Estadual de Campinas; 2007. 159 p.
13. Mezzomo CL, Baesso JS, Athayde ML, Dias RF, Giacchini V. O papel do contexto fonológico no desenvolvimento da fala: implicações para a terapia dos desvios fonológicos evolutivos. Letras de Hoje. 2008;43(3):15-21.

14. Galea DE, Wertzner HF. Comparação entre onset e coda silábica durante a aquisição fonológica. Rev Soc Bras Fonoaudiol. 2010;15(1):103-7.

15. Macken MA, Barton D. The acquisition of the voicing contrast in English: study of voice onset time in word-initial stop consonants. J Child Lang.1980;7(1):41-74.

16. Berti LC, Pagliuso A, Lacava F. Instrumento de avaliação de fala para análise acústica (IAFAC) baseado em critérios linguísticos. Rev Soc Bras de Fonoaudiol. 2009;14(3):305-14.

17. Wertzner HF, Alves RR, Ramos AC. Análise do desenvolvimento das habilidades diadococinéticas orais em crianças normais e com transtorno fonológico. Rev Soc Bras Fonoaudiol. 2008;13(2):136-42.

18. Castro MM, Wertzner HF. Influência das vogais na estimulabilidade dos sons liquidos. Rev CEFAC. 2009;11(2):169-74.

19. Nittrouer $S$. The emergence of mature gestural patterns is not uniform. Evidence from an acoustic study. J Speech Hear Res. 1993;36(5):95972.

20. Nittrouer S. The discriminability and perceptual weighting of some acoustic cues to speech perception by three-year-olds. J Speech Hear Res. 1996;39(1):278-97.

21. Scobbie JM, Gibbon F, Hardcastle WJ, Fletcher P. Covert contrast as a stage in the acquisition of phonetics and phonology. In: Broe MB, Pierrehumbert JB (Editors). Papers in Laboratory Phonology V: Language Acquisition and the Lexicon. Cambridge: Cambridge University Press; 2000. p. 194-207.

22. Berti LC. Contrastes e contrastes encobertos na produção de fala de crianças. Pró-Fono. 2010;22(4):531-6. 
23. Li F, Edwards J, Beckman M. Contrast and covert contrast: the phonetic development of voiceless sibilant fricatives in English and Japanese toddlers. J Phonetics. 2009;37(2):189-211.

24. Kent RD, Read C. The acoustic analysis of speech. San Diego: Singular Publishing Group; 1992.

25. Ferraz IS. Características fonético-acústicas do /r/ retroflexo do português brasileiro: dados de informantes de Pato Branco (PR) [dissertação]. Curitiba: Universidade Federal do Paraná; 2005.
26. Wertzner HF, Pagan-Neves LO, Castro MM. Análise acústica e índice de estimulabilidade nos sons líquidos do português brasileiro. Rev CEFAC. 2007;9(3):339-50.

27. Mezzomo CL, Mota HB, Dias RF, Giacchini V. O uso da estratégia de alongamento compensatório em crianças com desenvolvimento fonológico normal e desviante. Letras de Hoje. 2008;43(3):35-41. 